\title{
ÉTICA BIBLIOTECÁRIA EM UNIVERSIDADES DO NORTE E NORDESTE DO BRASIL
}

\section{LA ÉTICA EN LA BIBLIOTECA UNIVERSITARIA DE NORTE Y NORESTE DE BRASIL}

Francisco das Chagas de Souza - chagas.cin83@yahoo.com Doutor em Educação pela Universidade Metodista de Piracicaba.

Professor da Universidade Federal de Santa Catarina (UFSC).

\section{RESUMO}

Introdução: As noções de responsabilidade social e de boa prática profissional estão se constituindo cada vez mais em referência para a atuação de empresas, governos e profissões. Os bibliotecários brasileiros encontram tais noções no Código de Ética do Bibliotecário e, internacionalmente, no Código de Ética do bibliotecário e de outros profissionais da informação, da IFLA.

Objetivo: Analisar o discurso consolidado nos portais de bibliotecas de dez universidades das regiões Norte e Nordeste do Brasil.

Metodologia: Análise do discurso textual.

Resultados: Síntese das posturas manifestas nos portais das Bibliotecas Universitárias, referentes às condutas que adotam na relação com seus usuários.

Conclusões: O bibliotecário não distingue sua ética pessoal daquela disposta na norma ética de sua profissão. Enquanto sua ética pessoal é utilitária, a ética profissional disposta no código de ética do bibliotecário brasileiro é deontológica. Os portais de Bibliotecas Universitárias estudadas oferecem uma expressão muito aquém do desejável em se tratando de ética profissional bibliotecária.

Palavras-chave: Ética profissional. Ética do bibliotecário. Brasil - biblioteca universitária. 


\section{INTRODUÇÃO}

Nos últimos anos as organizações empresariais e governamentais em âmbito internacional têm feito um esforço evidente no sentido de apontar para a atuação com responsabilidade social (CASTRO, 2008; MOTTA; BANDEIRA, 2003; TONIN, 2010). Nesse aspecto, acentuam como propósito principal o desenvolvimento que ações que atendam ao princípio da boa prática profissional. Isso também tem enorme efeito como referência às práticas profissionais (IFLA, 2012) e serviria para assegurar a busca do reconhecimento social das respectivas profissões, mirando a percepção de sua relevância no futuro.

Por esse ângulo de avaliação, todo e qualquer esforço realizado para melhor compreensão e explicação dessa profissão em dada sociedade é, supostamente, do interesse dos profissionais já em exercício. Tal orientação está relacionada com a ideia de que ao se conhecer melhor dada profissão se the assegura legitimação. Por esse entendimento, é de boa prática profissional auxiliar com dados apropriados o desenvolvimento de estudos que levem ao conhecimento mais fundo de uma profissão. Deste modo, o Código de Ética do Bibliotecário Brasileiro (CEBB) (CONSELHO FEDERAL DE BIBLIOTECONOMIA, 2002) orienta que os profissionais colaborem com estudos e pesquisas que possam produzir um mais amplo conhecimento dessa profissão e da prática de seus profissionais. Entretanto, isso nem sempre acontece. A pesquisa que dá origem a esta comunicação se constitui como segunda etapa de um projeto realizado ao longo de mais de dois anos. Em sua primeira etapa, ela sofreu com más práticas de bibliotecários que atuam em universidades. O relatório da primeira etapa (SOUZA, 2012) traz uma nota metodológica que demonstra essa afirmação. A coleta de dados que envolveria os bibliotecários como entrevistados presenciais não foi possível e, por isso, buscou-se outra fonte de consolidação dos seus discursos, ou seja, os portais das bibliotecas/sistemas de bibliotecas dos quais fazem parte.

Com isso, fez-se o devido ajuste do objetivo geral inicialmente dado: "Compreender a contribuição que o Código de Ética do Bibliotecário Brasileiro (CEBB) oferece para o bibliotecário quanto à sua identidade profissional e quanto à sua inserção na sociedade como pessoa portadora da profissão de bibliotecário." Só assim foi possível a realização do estudo em 2012 e sua segunda etapa em 2013 (SOUZA, 2013, p. 4). 
De acordo com a proposição inicial, que implicava na busca das percepções de valor e sentido do CEBB,

[...] a noção de valor [...] tem relação com o suporte que o bibliotecário acredita encontrar no CEBB para realçar sua condição de cidadão civil, particularmente, no que diz respeito às suas potencialidades econômicas e políticas, a noção de sentido [...] tem a ver com o suporte que o bibliotecário acredita encontrar no CEBB para realçar sua condição de autoridade profissional, particularmente no que diz respeito ao desempenho de sua profissão no interior das relações sociais. (SOUZA, 2012, p. 5).

De igual modo que na primeira etapa da investigação, nesta se estudou o discurso consolidado nos portais do grupo constituído pelas bibliotecas de dez universidades das regiões Norte e Nordeste do Brasil com o melhor posicionamento em qualidade na pesquisa, no Ranking Universitário Folha (RUF) 2012. Tais discursos foram tomados como podendo refletir a ética profissional do bibliotecário, na medida em que reiteradamente os bibliotecários se apresentam como dirigentes de bibliotecas nas Instituições de Ensino Superior (IES) em que atuam.

Portanto, o objetivo desta comunicação é trazer os resultados obtidos nesta segunda etapa de pesquisa para o debate acadêmico no ambiente de pesquisa em Ciência da Informação, através de periódico especializado.

\section{PROCEDIMENTOS METODOLÓGICOS}

$\mathrm{Na}$ investigação, partiu-se da ideia de que a atuação da biblioteca universitária $(\mathrm{BU})$ deve refletir uma conduta bibliotecária plenamente ética acionada pela noção de comunicação-como-cuidado e cuidado-como-acolhimento e acolhimento como mutualidade-de-construção de sentido do bem agir. Assim, caminhou-se para a análise dos portais das BUs a fim de observar como a comunicação apresentada nesse canal, mantido por essas IES, expressa uma ética bibliotecária nos vários segmentos discursivos veiculados pelos portais, isto é, como eles se apresentam e se eles apresentam um discurso de recorte estratégico que exponha visão, missão, objetivos, finalidades, serviços, regulamentos, etc. e como o fazem, que tipo de atitude está expresso no que fazem, com que perspectiva de relacionamento o fazem.

O universo do estudo global, em suas duas etapas, foi composto por 190 IES que é o tamanho do conjunto identificado no RUF-2012. Nele, estão incluídas as IES 
públicas e a IES privadas, das quais 102 são públicas, sendo 59 vinculadas à união, 37 aos estados e seis a municípios e 88 compõem o setor privado.

Desse universo, tomou-se como amostra as dez melhores IES das regiões norte e nordeste do Brasil pelo indicador qualidade da pesquisa, tendo como referência os critérios empregados pelo RUF-2012, com base nos dados de 2011. O RUF é mais um instrumento de avaliação das instituições que compõem o Sistema de Ensino Superior do País e que têm a estrutura de universidade. Sua diferença em comparação a outros instrumentos similares é que se trata de uma iniciativa privada de jornal brasileiro, que pode vir em sentido complementar aos recursos anteriormente existentes e, provavelmente, embutindo outros aspectos de criticidade necessários a uma visão mais ampla. De certa forma, responde a uma queixa oriunda de vários setores, acadêmicos, empresariais, etc., que costumavam reclamar da existência no país apenas dos sistemas oficiais de avaliação de desempenho das IES.

Algumas informações, de caracterização mais geral, foram buscadas nos sites das IES selecionadas: Universidade Federal do Ceará (UFC), Universidade Federal de Pernambuco (UFPE), Universidade Federal da Bahia (UFBA), Universidade Federal da Paraíba (UFPB), Universidade Federal do Rio Grande do Norte (UFRN), Universidade Federal Rural de Pernambuco (UFRPE), Universidade Federal do Pará (UFPA), Universidade Federal de Alagoas (UFAL), Universidade Federal de Campina Grande (UFCG) e Universidade Federal de Sergipe (UFS), mas a fonte mais utilizada foi o portal de cada sistema bibliotecário nelas existentes.

Nos sites ou portais analisados foram coletados dados referentes a finalidades e valores expressos pela biblioteca; regulamentação das operações; serviços ofertados; comunicação sobre conduta profissional; público atendido com serviço de empréstimo bibliográfico; material emprestado, quantidade e tempo de empréstimo; estímulo à devolução do material emprestado no prazo contratado e quaisquer comunicações que visam afirmar sobre a conduta profissional delineada para o funcionamento da biblioteca.

Como instrumento para o registro do material coletado adotou-se uma planilha construída de maneira a relacionar cada sistema bibliotecário das IES selecionadas com as informações colhidas em seu portal por meio de uma busca individualizada. Em cada etapa de navegação no respectivo portal buscou-se colher 
dados sobre os tópicos mencionados no parágrafo anterior de modo a assegurar a uniformidade do processo de recolha.

Os dados foram coletados em vários momentos de navegação, no período que foi de julho a dezembro de 2013. No caso de ter sido possível a coleta completa dos dados de uma determinada biblioteca, fez-se o esforço de ali retornar a fim de averiguar a inserção de informação nova. Isso servia, nos poucos casos em que se percebeu algo novo como conteúdo ou forma, para confirmar a maior ou menor tendência em melhor dar atenção ou cuidado para o público da instituição.

Para efeito de tratamento e análise os dados discursivos encontrados foram agregados em tabelas e analisados com base em cinco valores profissionais expressos no Código de Ética do bibliotecário brasileiro: dignidade, respeito, responsabilidade, compromisso e solidariedade.

\section{CONTEXTO SOCIAL E ECONÔMICO DOS ESTADOS SEDE DAS UNIVERSIDADES}

Alagoas, Bahia, Ceará, Paraíba, Pernambuco, Rio Grande do Norte e Sergipe são os sete estados do Nordeste e Pará o único estado do Norte onde estão sediadas as dez IES cujas bibliotecas foram estudadas. No esforço de melhor compreender o modo de atuação dessas bibliotecas buscou-se reunir, no quadro síntese abaixo, dados de maior amplitude relativos a aspectos demográficos, geográficos, econômicos e educacionais desses Estados.

Esses dados, quando comparados com os índices nacionais, demonstram uma significativa precariedade local, sobretudo quanto à renda média domiciliar per capita, o percentual de pessoas vivendo em situação de extrema pobreza pelo critério internacional de renda mínima, o contingente de estudantes em IES privadas, o percentual de estudantes de 18 a 24 anos frequentando o ensino superior, a proporção de pessoas com 25 anos de idade ou mais com 15 anos ou mais de estudo e o percentual de famílias com crianças de zero a 14 anos que têm dificuldade ou muita dificuldade para chegar ao final do mês com o rendimento monetário familiar que obtém. 
Quadro 1 - Síntese

Algumas características dos Estados das regiões Norte e Nordeste do Brasil sedes das dez IES com maior qualidade em pesquisa - RUF 2012

\begin{tabular}{|c|c|c|c|c|c|c|c|c|c|c|}
\hline $\begin{array}{l}\text { IES } \\
(2011-2012)\end{array}$ & $\begin{array}{l}\text { Total da } \\
\text { população } \\
\text { residente no } \\
\text { Estado } \\
(2010)\end{array}$ & $\begin{array}{l}\text { Núme- } \\
\text { ro de } \\
\text { municí } \\
\text {-pios } \\
(2010)\end{array}$ & $\begin{array}{l}\text { PIB do estado } \\
\text { em R\$ mil } \\
(2011)(1)\end{array}$ & \begin{tabular}{|l|} 
Renda \\
média \\
domiciliar \\
per capita \\
em R\$ \\
$(2010)(2)$
\end{tabular} & $\begin{array}{l}\% \text { da } \\
\text { popula- } \\
\text { ção em } \\
\text { extrem } \\
\text { a } \\
\text { pobrez } \\
\text { a } \\
(2010) \\
(3)\end{array}$ & $\begin{array}{l}\text { Densida- } \\
\text { de } \\
\text { demográ- } \\
\text { fica } \\
\left(\mathrm{Hab} / \mathrm{Km}^{2}\right. \\
-2010)\end{array}$ & $\begin{array}{l}\% \text { das } \\
\text { pessoas que } \\
\text { frequentam o } \\
\text { ensino } \\
\text { superior } \\
\text { público } \\
\rightarrow \text { privado } \\
\text { (2009) }\end{array}$ & $\begin{array}{l}\% \text { de } \\
\text { estudantes de } \\
18 \text { a } 24 \text { anos } \\
\text { do Estado } \\
\text { frequentando } \\
\text { o ensino } \\
\text { superior } \\
(2009)(4)\end{array}$ & $\begin{array}{l}\text { \% de pessoas } \\
\text { com } 25 \text { anos } \\
\text { de idade ou } \\
\text { mais com } 15 \\
\text { anos ou mais } \\
\text { de estudo } \\
(2009)(5)\end{array}$ & $\begin{array}{l}\text { \% de familias } \\
\text { com crianças } \\
\text { de } 0 \text { a } 14 \text { anos } \\
\text { de idade com } \\
\text { "muita } \\
\text { dificuldade" e } \\
\text { "dificuldade" } \\
\text { para chegar } \\
\text { ao fim do mês } \\
\text { com o } \\
\text { rendimento } \\
\text { monetário } \\
\text { familiar (6) }\end{array}$ \\
\hline UFC $12 \mathrm{a} . / 1$ & 8.452 .381 & 184 & 87.982 .000 & 445,88 & 18,4 & 56,76 & $38,5 \rightarrow 61,5$ & 37,5 & 6,2 & 52,9 \\
\hline $\begin{array}{l}\text { UFPE } 16^{\mathrm{a}} .12 \\
\text { UFRPE } 34^{\mathrm{a}} . / 6\end{array}$ & 8.796 .448 & 185 & 104.394 .000 & 508,82 & $\frac{10,7}{16,1}$ & 89,63 & $24,8->75,2$ & 32,4 & 7,2 & 57,1 \\
\hline UFBA $19^{\mathrm{a}} .13$ & 14.016 .906 & 417 & 159.869 .000 & 481,18 & 17,7 & 24,82 & 25,3 -> 74,7 & 24,2 & 5,3 & 58,1 \\
\hline $\begin{array}{ll}\text { UFPB } & 28^{\mathrm{a}} . / 4 \\
\text { UFCG } & 42^{\mathrm{a}} . / 9\end{array}$ & 3.766 .528 & 223 & 35.444 .000 & 462,29 & 16,3 & 66,70 & $44,5->55,5$ & 34,4 & 7,4 & 56,2 \\
\hline UFRN $29^{\mathrm{a}} .15$ & 3.168 .027 & 167 & 36.103 .000 & 531,56 & 13,0 & 59,99 & $37,6->62,4$ & 35,3 & 6,5 & 50,4 \\
\hline UFPA $35^{\mathrm{a}} .17$ & 7.581 .051 & 144 & 88.371 .000 & 429,57 & 19,2 & 6,07 & $35,8>64,2$ & 23,2 & 5,3 & 48,7 \\
\hline UFAL $38^{\mathrm{a}} . / 8$ & 3.120494 & 102 & 28.540 .000 & 421,32 & 20,5 & 112,33 & $28,7>71,3$ & 31,1 & 5,9 & 59,5 \\
\hline UFS $43^{\mathrm{a}} . / 10$ & 2.068 .017 & 75 & 26.199 .000 & 508,20 & 15,3 & 94,35 & $30,6>69,4$ & 43,1 & 7,7 & 55,5 \\
\hline
\end{tabular}

(1) Comparativamente, São Paulo $=1349.465 .000 /$ Rio de Janeiro $=462376.000$

(2) Comparativamente: Distrito Federal $=1.665,42 / \mathrm{São}$ Paulo $=1.036,51$

(3) Com base em valor proposto pelo Banco Mundial, uma receita per capita abaixo de $R \$$ 70,00 demarca a situação de extrema pobreza. Fonte: htto://pt.wikipedia.org/wiki/Anexo:Lista de

estados do Brasil por incid\%C3\%AAncia da pobreza. Comparativamente, Santa Catarina $=1,7 /$ Distrito Federal $=1,9 /$ São Paulo $=2,7$

(4) Média nacional $=48,1$

(5) Média nacional $=10,1$

(6) Média nacional $=44,5$

Fonte: Wikipédia, 2014.

Confrontando-se esses dados com os dados nacionais e cruzando-se partes desses dados em cada Estado tratado, percebe-se que políticas adotadas a partir de critérios homogeneizadores importados por via de um discurso central da educação, tendem a expor a força das desigualdades existentes e até reforçar as diferentes formas de exclusão das pessoas. Por exemplo, no ano de 2010, enquanto a renda média domiciliar per capita no Distrito Federal era de $\mathrm{R} \$ 1.665,42$ reais e em São Paulo era de $\mathrm{R} \$ 1.036,51$ reais nos Estados das IES estudadas aquele onde se encontrou o maior valor (Rio Grande do Norte) alcançava $R \$ 531,56$ reais, ou seja, menos de $1 / 3$ da renda alcançada no Distrito Federal e em torno da metade daquela alcançada em São Paulo.

Quando se olha para o indicador "extrema pobreza" vê-se que enquanto os Estados de Santa Catarina tem 1,7\%, Distrito Federal tem 1,9\% e São Paulo tem 2,7\% de pessoas vivendo nessa condição, nos Estados onde se situam as IES estudadas nesta pesquisa o que tinha o menor percentual (Rio Grande do Norte) alcançava $13 \%$, ou seja, oito vezes mais gente vivendo em extrema pobreza que no Estado de Santa Catarina, chegando ao extremo de num Estado sede de uma das IES estudadas (Alagoas) vê-se esse número ultrapassar os vinte por cento da 
população em situação de extrema pobreza. Tal dado é mais que confirmado quando cruzado com outro indicador referente à condição de sobrevivência: a dificuldade ou muita dificuldade das famílias com crianças de 0 a 14 anos para chegar o fim do mês com o rendimento monetário familiar auferido. Em âmbito nacional, a incidência média dessa condição é de $44,5 \%$. Nos estados onde se localizam as IES estudadas o valor mais baixo (Pará) é de $48,7 \%$ das famílias nessa condição; todos registram mais de $50 \%$ e no extremo superior em um dos estados (Alagoas) esse índice chega quase a $60 \%$.

Nesse mesmo contexto social e econômico, com a presença de famílias com tantas limitações econômicas, ocorre a oferta de ensino superior predominantemente privado. Em um dos estados arrolados no estudo (Pernambuco), ultrapassa a $75 \%$ o percentual de estudantes que frequenta o ensino superior não público. Na faixa etária de 18 a 24 anos de idade, em que costumeiramente se vê a concentração do maior número de estudantes em ensino superior, há Estado parte do estudo (Pará) em que esse número mal supera os $23 \%$ e, no conjunto desses oito estados, como média, mal supera os $32 \%$, sendo um dos possíveis fatores a determinar o atraso ou abandono escolar altamente incidente nas regiões Norte e Nordeste. Outra característica negativamente marcante é que enquanto no Brasil a proporção de crianças de 7 a 14 anos de idade que não sabe ler nem escrever é de 6,8\%, na Região norte ela vai a 10,1\% e na Região Nordeste a 11,8\%. Já para o grupo de 15 a 24 anos de idade esse índice para o Brasil é de $1,9 \%$ e para as regiões Norte e Nordeste é, respectivamente, de 2,2\% e 3,9\%.

Tais dados revelam insuficiências sociais e econômicas a serem resolvidas com apropriadas ações decorrentes do estabelecimento de políticas públicas e políticas profissionais. Os fenômenos expressos por esses indicadores provavelmente interferem de forma negativa sobre toda e qualquer expectativa de progresso econômico e social nessas regiões. Também podem afirmar como injustas as ações sustentadas em discursos que carregam preconceitos tendentes ao isolacionismo, individualismo, exclusivismo dos grupos estabelecidos como suas elites políticas, acadêmicas e profissionais, até por que essas representam uma proporção muito pequena da população. Em reforço a essa percepção, os dados reunidos indicam que o percentual de pessoas com idade de 25 anos ou mais, que obtiveram 15 anos ou mais de estudos, no Estado com melhor situação dentre aqueles que fazem parte do estudo (Sergipe), mal ultrapassa a $7,5 \%$ e no limite 
inferior vai pouco além de cinco por cento.

\section{AS DEZ MELHORES UNIVERSIDADES}

O ensino superior no Brasil tem uma história que pode ser dividida em duas etapas. A primeira etapa guarda relação com a implantação no início do século XIX, das primeiras escolas de formação de médicos, engenheiros e bacharéis em direito. Isso se deu a partir da chegada da corte portuguesa em 1808. Quase como regra geral, no século XX todas essas primeiras instituições de ensino deram origem ou foram incorporadas às universidades constituídas pelo Estado brasileiro.

A segunda etapa deu-se com a criação de instituições projetadas já com o propósito de se constituírem universidades, das quais a primeira foi a USP em 1934.

Esse atraso na constituição da universidade no Brasil tem como suposto determinante o receio do Estado português, senhor do território brasileiro até o início do século XIX, de que nesta terra se constituísse por meio do ensino superior uma classe de pessoas dotadas de condições para buscar a emancipação política. Provavelmente, com a constituição de uma elite intelectual em universidades locais, um movimento com esse propósito obtivesse algum sucesso. De certa maneira, a base para que o Brasil viesse a se emancipar do Estado português se deu pelo caminho político de forma inesperada, isto é, pela vinda para este território dos governantes portugueses enquanto fugiam do enfrentamento direto com o imperador francês Napoleão Bonaparte, que ameaçou invadir e dominar o território português. Tal episódio evidencia de maneira bastante forte a incapacidade do Estado português à época de enxergar o Brasil como um território com destino diferente de uma base para a extração de riquezas minerais e vegetais. Naquele período, dar asas para que neste território se formasse uma nação independente, com grupos sociais tendo largo acesso à educação e ampliação do engenho empreendedor moderno, poderia ser tomado como potencialização da abreviação do domínio colonial focado na extração dessas riquezas.

Mesmo a educação superior já implantada era de acesso muito restrito até às primeiras décadas do século $X X$ e cobria poucos campos, especialmente em consequência das restrições existentes. No final dos anos da década de 1950 e primeiros anos da década de 1960 era dirigida para poucas áreas de formação profissional e, paulatinamente, incorporava a preparação para novas profissões que a economia do país passava a requisitar. 
Assim, a universidade enquanto uma unidade integradora de vários campos de saber, a partir de uma concepção global consolidada em torno de uma faculdade de Filosofia, Ciências e Letras, surgiu no Brasil há menos de um século. Sua incipiência é de tal ordem, que no texto do projeto de criação da Universidade de Brasília (UNB) no início dos anos da década de 1960, está categoricamente afirmado que a estrutura existente no país no final dos anos 1950 a título de universidade poderia ser caracterizada como atrasada, quase inoperante e sem condições de assegurar o progresso econômico da nação (RIBEIRO, 2007).

Mesmo com essa caracterização, é fato que no final dos anos 1950 e início dos anos 1960 muitas universidades foram formal e legalmente criadas em vários Estados da federação. Isso se deu pela mera reunião de escolas isoladas neles instaladas em suas capitais como estabelecimentos privados ou subvencionados pelos Estados e pela União, sem autossuficiência econômica. Como se verá mais adiante nesta comunicação, a quase totalidade das IES abrangidas por esta pesquisa resulta desse modelo e é criada nessa época.

Nas condições operacionais dadas no momento da pesquisa, constatou-se que nas IES estudadas há a oferta de dezenas de Cursos de Pós-Graduação, incluindo os níveis de mestrado e de doutorado; em todas há também pelos menos mais de uma centena de Grupos de Pesquisa cadastrados no diretório do Conselho Nacional de Desenvolvimento Científico e Tecnológico (CNPq). Seja pela titulação, seja pelo envolvimento com pesquisa, seja porque constitui elite intelectual nos respectivos estados, os docentes e pesquisadores que nelas atuam, certamente, exercem liderança acadêmica. Com esse perfil, é razoável esperar que tenham presença e participação na vida de suas instituições capazes de contribuir com o pensamento e fomento de uma modernização nas estruturas das IES onde atuam. $E$, se esta conduta for realizada é de esperar-se seu reflexo em todos os setores dos respectivos Estados e em benefício de suas populações. Isso, supostamente, implicaria a existência de bibliotecas universitárias em que o exercício de boas práticas profissionais, ou o agir eticamente mais condizente com a modificação do contexto social e econômico para melhor, fosse um fato bem evidente.

A seguir se dá uma breve descrição das IES na ordem de classificação em que estão posicionadas quanto à qualidade de sua pesquisa, acentuando o momento de sua criação e as bases de sua formação. 
1 - A UFC nasceu e está sediada na cidade de Fortaleza, como resultado de um amplo movimento de opinião pública. Criada pela Lei n. 2.373, em 16 de dezembro de 1954, e instalada em 25 de junho do ano seguinte, era constituída pela Escola de Agronomia, Faculdade de Direito, Faculdade de Medicina e Faculdade de Farmácia e Odontologia.

2 - A UFPE teve início em 11 de agosto de 1946, como Universidade do Recife (UR). Criada por meio do Decreto-Lei da Presidência da República o 9.388, de 20 de junho de 1946, reunia a Faculdade de Direito do Recife, a Escola de Engenharia de Pernambuco, a Faculdade de Medicina do Recife, com as escolas anexas de Odontologia e Farmácia, a Escola de Belas Artes de Pernambuco e a Faculdade de Filosofia do Recife.

3 - A UFBA remonta ao Colégio Médico-Cirúrgico da Bahia, criada pelo Príncipe Regente D.João, em 1808, origem da atual Faculdade de Medicina da Bahia. Mais tarde, foram criados e incorporados à Escola de Cirurgia os cursos de Farmácia, em 1832, e de Odontologia, em 1864. A atual Escola de Belas Artes também foi criada em 1877, com o nome de Academia de Belas Artes da Bahia. À sua criação, seguiram-se a da Faculdade de Direito (1891) e da Escola Politécnica da Bahia (1897). A Faculdade de Ciências Econômicas da Bahia e a Faculdade de Filosofia, Ciências e Letras surgiram em 1934 e 1941, respectivamente.

4 - A UFPB foi criada pela Lei Estadual 1.366, de 02 de dezembro de 1955, e instalada sob o nome de Universidade da Paraíba resultante da junção de algumas escolas superiores. Com a sua federalização, aprovada e promulgada pela Lei ㄲo. 3.835 de 13 de dezembro de 1960, foi transformada em Universidade Federal da Paraíba, incorporando as estruturas universitárias existentes nas cidades de João Pessoa e Campina Grande.

5 - A UFRN tem origem na Universidade do Rio Grande do Norte, criada em 25 de junho de 1958, através de lei estadual, e federalizada em 18 de dezembro de 1960. Instalada em 21 de março de 1959, foi formada a partir de faculdades e escolas de nível superior já existentes em Natal, como a Faculdade de Farmácia e Odontologia; a Faculdade de Direito; a Faculdade de Medicina; a Escola de Engenharia, entre outras.

6 - A UFRPE tem sua origem datada de 3 de novembro de 1912, na cidade de Olinda, a partir da criação das Escolas Superiores de Agricultura e Medicina Veterinária São Bento, com oferta dos cursos de Agronomia e Medicina Veterinária. 
7 - A UFPA foi criada pela Lei ํㅜ 3.191, de 2 de julho de 1957, após cinco anos de tramitação legislativa. Congregou as sete faculdades federais, estaduais e privadas existentes em Belém: Medicina, Direito, Farmácia, Engenharia, Odontologia, Filosofia, Ciências e Letras e Ciências Econômicas, Contábeis e Atuariais.

8 - A UFAL foi criada em 25 de janeiro de 1961, reunindo as Faculdades de Direito (1933); Medicina (1951), Filosofia (1952), Economia (1954), Engenharia (1955) e Odontologia (1957).

9 - A UFCG foi criada pela Lei no. 10.419 de 09/04/2002, pelo desmembramento da Universidade Federal da Paraíba (UFPB). Desde sua criação, a UFCG conta com a estrutura multicampi e a sede de sua Reitoria está na cidade de Campina Grande.

10 - A UFS foi criada em 1967, pelo Decreto-Lei nำ269, com a reunião de: Faculdade de Ciências Econômicas e da Escola de Química (1948), Faculdade de Direito e Faculdade Católica de Filosofia (1950), Escola de Serviço Social (1954) e Faculdade de Ciências Médicas (1961). Antes disso, em 1963, a então Secretaria de Educação do Estado deu início ao processo de criação da universidade.

\section{$5 \quad$ AS BIBLIOTECAS DAS UNIVERSIDADES SELECIONADAS}

Nessas IES parece ocorrer um aparente distanciamento ou pouca empatia entre os vários setores da gestão acadêmica e biblioteca, refletindo de certa maneira o modo como se exerce o poder político e administrativo nas universidades estudadas. De um ou outro jeito, essa circunstância estará refletida nos discursos que são apresentados nos portais das bibliotecas ou sistemas analisados. Desse modo, o que vem a seguir captado nos sites/portais das bibliotecas centrais ou sedes dos sistemas de bibliotecas dessas IES, em sua própria linguagem, descreve suas características gerais.

$\mathrm{Na}$ UFC, de 1955 a 1969, foram instaladas 17 bibliotecas pertencentes às unidades de ensino surgidas após a criação da Universidade. Com implantação da Reforma Universitária (1972) e a instituição dos Centros, teve início a fusão de bibliotecas de áreas correlatas, em decorrência da extinção de alguns institutos de pesquisa. Atualmente, o Sistema de Bibliotecas, coordenado pela Biblioteca Universitária, compreende 12 bibliotecas em Fortaleza e 5 no interior do Estado. 
Na UFPE, o Sistema é formado pela Biblioteca Central e por 12 unidades localizadas nos Centros Acadêmicos, Colégio de Aplicação. Juntas, reúnem cerca de 263.106 títulos com 951.280 exemplares

$\mathrm{Na}$ UFBA, o Sistema de Bibliotecas é constituído por um conjunto de 29 Bibliotecas, instaladas nos diversos campi, encontrando-se segmentadas em cinco Áreas do Conhecimento. Além dessas bibliotecas classificadas nas referidas Áreas do Conhecimento, o Sistema também engloba bibliotecas instaladas em Órgãos Suplementares da Universidade.

Na UFPB, o Sistema de Bibliotecas compreende a Biblioteca Central e as Setoriais.

$\mathrm{Na}$ UFRN, o Sistema de Bibliotecas é constituído pela Biblioteca Central e pelas bibliotecas setoriais que funcionam em Centros Acadêmicos, Unidades Acadêmicas Especializadas, Unidades Suplementares e demais unidades acadêmicas localizadas em Natal e/ou no interior do Estado.

$\mathrm{Na}$ UFRPE, a Biblioteca Central tem origem no ano de 1914 quando se caracterizava como "depósito de livros" dos Cursos existentes nas Escolas Superiores de Agricultura e Medicina Veterinária "São Bento", localizados inicialmente em Olinda, PE. Em 1938 com a mudança desses Cursos para o bairro de Dois Irmãos, no município do Recife, o acervo foi igualmente transferido. De 1947 a 1955 a Biblioteca denominou-se "Biblioteca da Universidade Rural de Pernambuco (B-UFRPE)". A partir do Decreto o 93 de 03/11/1975, a Biblioteca passou a denominar-se Biblioteca Central da Universidade Federal Rural de Pernambuco (BCUFRPE).

$\mathrm{Na}$ UFPA, há 37 bibliotecas universitárias compondo o Sistema de Bibliotecas, coordenadas tecnicamente pela Biblioteca Central. A maioria (19), está localizada no campus Belém, 8 em bairros da cidade e 10 nos campi dos municípios de Abaetetuba, Altamira, Bragança, Breves, Cametá, Castanhal, Marabá (I e II), Tucurui e Soure.

Na UFAL, o Sistema de Bibliotecas é composto pela Biblioteca Central e 7 Bibliotecas Setoriais.

Na UFCG, o Sistema de Bibliotecas é composto pela Biblioteca Central e 9 Bibliotecas Setoriais. 
Na UFS, criou-se a Biblioteca Central em 1979 com a finalidade de planejar e incorporar todas as bibliotecas e coordenar a instalação definitiva para o campus universitário no ano de 1980.

\section{QUADRO DAS PRÁTICAS BIBLIOTECÁRIAS EVIDENCIADO NOS PORTAIS DAS BIBLIOTECAS DAS IES SELECIONADAS}

A coleta de dados que se fez nos portais das bibliotecas ou sistemas bibliotecários das dez IES selecionadas para o estudo, tendo por base as boas práticas que podem ser construídas a partir dos valores mais relevantes dispostos no CEBB, gerou um corpus discursivo que uma vez tratado e analisado permitiu o agrupamento das condutas desenvolvidas nessas instituições na sua relação com seus usuários. É esta síntese que vem a seguir.

\subsection{Finalidades e Valores Expressos pela Biblioteca}

Ao explicitar os termos designativos de suas finalidades as Bibliotecas analisadas chegam a exibir como predominante o termo "Missão" e em segundo lugar o termo "Visão". Ao se comparar o presente resultado com o obtido na primeira etapa da pesquisa, isto é, o momento em que foram analisadas as bibliotecas de IES do Sul, Sudeste e Centro Oeste, observa-se que aquelas empregaram mais termos. Nas bibliotecas do Norte e Nordeste foram mencionados quatro termos: Missão, Visão, Valores e Objetivos; nas do Sul, Sudeste e Centro Oeste se chegou a sete termos: Missão, Visão, Valores, objetivos, Finalidade, Função e atribuições. Uma questão pode ser levantada diante desta constatação, ou seja, o que o emprego de menor ou maior número de termos representa de melhor ou pior na conduta profissional e resultado produzido quando se coloca frente a frente $o$ posicionamento dos dois grupos de bibliotecários: aqueles das dez IES que são as primeiras em qualidade de pesquisa e estes de bibliotecas de IES que constituem as dez primeiras quando se vê apenas o lugar geográfico, mas não exatamente a ordem dada pelo valor alcançado, o contexto atendido, o sentimento de respeito para com o usuário e para com a sociedade como um todo?

\subsection{Regulamentação das Operações}

Há dois aspectos que se pode considerar como relevantes na relação de 
serviço direta que uma instituição trava com o público, o primeiro é reconhecer quais são os dispositivos que impõem as condutas, isto é, quais os distintos tipos de formalizações legais adotados; o segundo é identificar de onde emanam tais dispositivos. Sob esta perspectiva, conhecer com quais instrumentos formais as instituições se autorregulam e atuam e onde eles foram gerados, para saber sobre o seu potencial legitimador, permite perceber o potencial de diálogo que embasa o funcionamento, no caso deste estudo, das bibliotecas das IES das regiões Norte e Nordeste aqui envolvidas.

O resultado obtido, considerando quantidade e teor dos instrumentos de regulação mostrou uma relação muito limitadora de boas práticas políticas, isto é, de composição entre grupos para formular as políticas que possam melhor respeitar as diferenças existentes nas respectivas comunidades universitárias. Uma amostra dessa limitação é a utilização em alguns casos, do órgão máximo de política universitária para deliberar sobre o valor financeiro da taxa de multa a ser cobrada dos usuários que atrasam a devolução de materiais emprestados.

\subsection{Serviços Ofertados}

Nas bibliotecas das IES analisadas tanto há pobreza quanto há excesso de informações e de caracterização do que constitui serviços. Por exemplo, são identificados como serviços: perguntas frequentes, cadastro, bibliocanto, nada consta. Entretanto, embora todas ofereçam o empréstimo domiciliar não são todas que o informam em seu portal. Isso leva ao questionamento seguinte: o que desejam ressaltar no primeiro caso e o que desejam deixar obscuro no segundo?

De outro lado, pelo elenco de serviços ofertados e tendo em vista que todas são bibliotecas de instituições que atuam no desenvolvimento de ensino, pesquisa e extensão, que singularidade jurídica, normativa e operacional justifica uma UFPE ou uma UFPA fazerem a descrição de serviços com muito mais detalhes que as demais? Parte dos serviços que não estão explicitados, caso existam, e há evidências de que existem, se expostos não gerariam melhor expressão de responsabilidade e compromisso social com o usuário? Essa omissão, se ocorre, é um aspecto relevante a ser examinado, pois revela a prática de uma politica de mau acolhimento e contradita, por exemplo, o Código de Ética da IFLA. 


\subsection{Comunicação Mediadora}

Neste estudo, não se fez testes sobre a efetividade das modalidades de relacionamento/comunicação que as bibliotecas das IES analisadas oferecem em seus portais, pois essa ação estava fora do escopo da investigação. Entretanto, diferentemente do canal "e-sic" que tende a ser uma denominação padrão do serviço instituído a partir da Lei 12.527/11 - "de Acesso à Informação - LAl”, (BRASIL. Lei...) os portais das BUs estudadas expõem várias denominações e designam várias estratégias para evidenciar esse canal. Essa diversidade, tendo em vista o discurso e a tradição padronizadora racional da prática bibliotecária, fica razoavelmente incompreensível, podendo suscitar dúvidas se não se trata também de uma forma de ser menos transparente. Se for isso que está na base dessa diversidade de termos ainda uma vez mais se pode tomar como reforçada a ideia da prática que efetiva uma politica de mau acolhimento.

Isso se torna um tanto mais grave como postura da biblioteca, quando se confronta a conduta com os termos da LAI. Tal Lei foi sancionada com o objetivo de regulamentar dispositivo constante no artigo 5․ da Constituição Federal de 1988 e também para dar forma ou orientação a um modo de agir da estrutura do Estado. Lamentavelmente, na sua fase de implementação, esta Lei tem servido para demonstrar o despreparo das equipes profissionais atuantes em várias instituições públicas para atender ao público. Muitas das IES vinculadas ao MEC demonstram esse despreparo, que também atinge seus portais bibliotecários.

\subsection{Público Atendido com Serviço de Empréstimo Bibliográfico}

Os portais bibliotecários estudados apontam bibliotecas que se destinam à comunidade universitária, isto é, aos docentes, estudantes e funcionários e, em caráter excepcional, atendendo a outras pessoas. Por definição de púbico que estabelecem, vê-se uma separação, um apartamento social. Aqueles que se identificam como vinculados formalmente à instituição podem utilizar o material em consulta local e em leitura domiciliar, os demais não.

Poder-se-á observar a partir disso que, apesar dos valores éticos responsabilidade e compromisso social constarem do Código de Ética do bibliotecário, nesta situação, esse valor aparece com duas facetas, deixando o bibliotecário a viver um dilema ético. Assim, o mais provável como deliberação que 
tomará será a efetivação de uma politica de mau acolhimento, ou seja, a pessoa não estando formalmente vinculada à universidade será uma pessoa a não existir domiciliarmente para essa biblioteca.

Uma questão que pode ser discutida, neste caso, é se toda instituição mantida com recursos públicos, no caso uma IES pública, teria a sua biblioteca como pública, isto é, permitindo o acesso universal da população aos serviços e, obviamente, aos acervos dessas bibliotecas. À primeira vista é um raciocínio correto ter as bibliotecas das IES públicas como abertas ao atendimento da população geral, incluída a possibilidade da retirada do material do recinto da biblioteca.

Se as IES há séculos têm sido acusadas, por conta do isolamento dos cientistas e de sua produção intelectual, de serem Torre de Marfim, o que se pode dizer da biblioteca da IES pública? Que é depósito de livros? Que é cemitério do saber? Seja qual for o qualificativo dado ele certamente refletirá o fato de como ela é vista pela maior parte da população, a qual, querendo ou não, custeia todas as operações e equipes de pessoas que atuam nessas bibliotecas. Mas a população, cujos membros têm constitucionalmente o domínio da cidadania, parece ser acolhida, em geral, como que por favor ou gentileza da instituição. Mas de fato não é por essa gentileza que a população deve ser beneficiada, e sim porque é ela a pagadora de impostos e, por isso, devendo ser contemplada com os serviços compatíveis com suas necessidades.

\subsection{Material Emprestado, Quantidade e Tempo de Empréstimo}

Os portais das BUs analisadas arrolam muitos dados a respeito do material emprestado, quantidade e tempo de empréstimo. Entretanto, o modo como estão dispostos, gera dificuldades para que se possa enxergar sua racionalidade intrínseca. Mesmo que se possa argumentar que esses dados correspondem às especificidades das respectivas comunidades, esses portais não permitem a um analista externo encontrar o que não foi exibido e há muito conteúdo evidentemente não exibido. Por exemplo, não se dispõe claramente dos documentos de Política de Formação e Desenvolvimento de Coleções, conforme recomenda o Código de Ética da IFLA; não se dispõe de avaliações sistemáticas, anuais ou plurianuais, sobre o funcionamento do Sistema de Bibliotecas, isto para falar apenas de instrumentos básicos à boa gestão de qualquer sistema bibliotecário, que respeite o princípio da transparência pública e da boa conduta ética. 
Com relação às categorias de usuários ou de agrupamento de usuários explicitados encontram-se dez designações distintas, no conjunto dessas IES. Contudo, nenhuma das categorias constantes nos portais tem entrada única ou inicia com Funcionários/servidores técnico-administrativos (STA). Caberia questionamento acerca do que isso quer traduzir. Seria o lugar secundário aceito pelos STAs nessas IES? Seria a admissão da ideia de menor responsabilidade institucional? Trata-se de questão que não é da conta dos bibliotecários atuantes nesses sistemas? Porém, se são esses bibliotecários que caracterizaram ou definem os usuários, qual a responsabilidade que têm nesse parcial ocultamento de membros sua própria categoria? Mas se essa caracterização não é de sua iniciativa quem está usando de poder para colocar toda uma categoria em segundo plano? Onde está a dignificação profissional do bibliotecário?

Outro aspecto a apreciar, a partir dos dados levantados nos portais, diz respeito aos tipos de materiais emprestáveis. Em algumas das BUs (UFPB, UFRN, UFPA, UFAL, UFS), explicitamente, só são emprestados livros. Na UFC (exceto o periódico impresso), UFPE e UFBA é emprestada uma categoria de material designada como material bibliográfico (Livros, periódicos impressos, teses, dissertações) e outra definida como material audiovisual. Já na UFPE é emprestado material bibliográfico, incluindo todas as demais categorias. Também, neste caso, não dá para o leitor externo saber por quais razões essas BUs distinguem dessa forma o material que pode ser emprestado.

Também merece análise o prazo máximo de empréstimo por tipo de material. Para o mesmo tipo de usuário, a considerar o tipo de material há respostas diferentes nas distintas BUs. Há 25 casos de dimensionamento do tempo máximo de empréstimo de material bibliográfico e livro. Esses 25 casos de dimensionamento do tempo máximo de empréstimo de material bibliográfico e livro, tem mais outras configurações se for acrescentada a gestão de empréstimo de material audiovisual e periódico impresso. Além disso, não é emprestado o mesmo número de itens a cada vez para alunos, professores e STAs, conforme a IES.

Essa malha disforme para um conjunto de instituições públicas federais de ensino, supostamente articuladas por uma mesma ideia de sistema, avaliadas pelas mesmas regras do Sistema Nacional de Avaliação do Ensino Superior (SINAES), financiada pela mesma fonte de recursos, com funcionários e bibliotecários sendo parte de uma mesma carreira e enquadramento funcional, é difícil de ser 
compreendida, pois mesmo o discurso do contexto local desautoriza, na medida em que requer ainda mais atenção e humanização. $O$ que talvez possa se imaginar como gênese desse quadro que beira ao caos, se visto como conjunto, é o coronelismo como modelo de conduta do poder. É a prática forjada em uma politica de mau acolhimento, que quando olhada com um pouco mais de atenção, se deixa revelar.

No entanto, tão distintos prazos para um mesmo tipo de público e mesmo tipo de material, embora ocorram em instituições diferentes, se dão em instituições que por fazerem parte de um sistema nacional poderiam adotar um padrão comum. E se isso é perfeitamente possível como se poderia achar mais justo o que se faz aqui do que se faz acolá? Como achar que o livro disposto aqui, o material audiovisual armazenado aqui é menos ou mais precioso que o que está acolá? A Constituição Federal de 1988 dispõe que todos os cidadãos devem ser tratados com igualdade, justiça e não sofram sequelas físicas, mentais ou morais decorrentes de sua relação com o Estado. No caso das BUs aqui examinadas, em relação aos serviços prestados aos usuários, se realiza como ação a atuação do Estado; e nesse caso, se são dirigidas por bibliotecários, há ainda para além das leis estatais, do código de ética do servidor público civil, etc., o código de ética do bibliotecário a ser seguido.

Para olhar de uma dimensão mais extrema, cabe ressaltar que a omissão de informação básica de interesse do usuário nos portais institucionais é passível de questionamento junto a órgãos de defesa dos direitos sociais. Nesse sentido, com relação à renovação de material sob empréstimo, há informação no portal da BU da UFPE (até 10 vezes, caso esteja sem reserva), UFBA (até oito vezes, caso esteja sem reserva), UFPB (uma só vez), UFS (até oito vezes, caso esteja sem reserva). Neste caso, o dado tem origem em quatro de um total de nove BUs, isto é, de menos da metade, e chama a atenção a mensagem da UFPB, pela renovação darse somente uma vez. Relativamente à reserva, a BU da UFBA é a única a expressála em seu portal.

\subsection{Estímulo à Devolução do Material Emprestado no Prazo Contratado}

Nos sistemas de BUs examinados a linguagem ou os termos da comunicação que relaciona o prestador de serviços com o seu usuário tende à rudeza e às vezes vai às minúcias de uma opressão do "proprietário ou guardião do patrimônio". Entende-se um pouco mais sobre isso, quando se vai à origem do que se conhece 
deste fenômeno social estabelecido como imposto tributário, se se estuda Elias em "O processo civilizador".

Dos oito portais examinados, pois continham essa informação disponível, encontra-se como estímulo ao cumprimento de prazos de devolução do material a imposição de multa por cinco BUs. As outras três impõem a suspensão: em uma, essa suspensão corresponde ao tempo equivalente àquele em que o material ficou retido pelo usuário; na segunda é o dobro do tempo e na terceira o triplo. As BUs que aplicam a multa financeira também suspendem o usuário, mesmo quando já devolveu o material com atraso, até que pague a multa aplicada. Nessa última situação, é questionável a imposição da multa, isto é, afirmar que vai fazê-lo implica em ter que admitir a aplicação de duas sanções para os usuários, em geral, os economicamente mais carentes, que mesmo repondo o material não possa de imediato satisfazer esse ônus: a suspensão não é estímulo para a devolução do material fora do prazo estipulado, mas é usurária e parte da iniciativa de quem se arroga o poder de fazer a expropriação, privando esses usuários de bem financeiro.

Ao se conhecer os dados contextuais sociais e econômicos onde se inserem essas bibliotecas, mostrados nas primeiras seções do relatório integral da pesquisa, dá para ver que essa imposição financeira é em si discutível quanto à justeza e mesmo quanto à justiça. Quanto à justeza se é moralmente correta e quanto à justiça, se ela afeta igualmente a todos e na devida proporção da pena. E se sabe que tende a não afetar igualmente a todos, pois ao ser em geral fixado o mesmo valor nominal para a multa, tomando a variável "dia de atraso", ele representará uma fração exígua do preço médio da obra utilizada nos cursos de maior custo, com livros que chegam a valores muito altos, ultrapassando algumas centenas de reais e representará uma fração muito maior do preço médio da obra requerida por cursos de menor custo em que o preço médio da obra mal alcança uma centena de reais. Mas se a multa financeira tem potencialmente essa faceta imoral e ainda pode agregar a suspensão, ela precisa ser bem discutida do ponto de vista da ética do bibliotecário. Por que nessas IES e em suas bibliotecas, todas vinculadas ao Governo Federal, tendo a mesma matriz orçamentária, dá-se tratamento distinto para o mesmo objeto? Aliás, o que leva as IES estudadas a terem um comportamento para com seus usuários no que toca à devolução do material bibliográfico fora do prazo, distinto daquele adotado nas IES de São Paulo, por exemplo? Em São Paulo, conforme os dados levantados na primeira etapa da 
pesquisa as IES públicas adotam o recurso da "suspensão", procedimento empregado pelas estaduais: USP, UNICAMP e UNESP, assim como pelas federais lá instaladas: UNIFESP e UFSCar.

A síntese que se obtém ao estudar essas IES do Nordeste e Norte do Brasil parece revelar algo mais que a racionalidade de uma leitura contextual de natureza social e econômica não conseguiria demonstrar. Ela reflete que o estímulo adotado pelas BUs e expresso em seus portais, nesse caso, talvez passe muito mais pelo acento da punição e expiação da carência. Se assim for, o corolário é: puna-se os carentes por serem carentes. Sendo isso, portanto, trata-se de uma questão de moralidade que vai além do alcance que uma ética bibliotecária - que pugna por responsabilidade, compromisso social e respeito ao usuário - poderá atender.

Isso implica que, nessas circunstâncias, o fator humanização nem sempre deve estar em evidência. Mas, a quem caberia evidenciar essa humanização? De imediato ao gestor do Sistema de Bibliotecas para que seu papel não se confunda com o de simples almoxarife de um armazém. Poder-se-á desenvolver esse fator com maior ou menor valoração moral, compromisso, responsabilidade social e respeito humano quando se vê os usuários como pessoas capazes de compreender com autonomia seu lugar na sociedade. Isso exige, então, que a linguagem adotada toque-os emocional e afetivamente e, portanto, que seja construída como fator estimulador.

\section{DA ETICIDADE EVIDENCIADA NAS PRÁTICAS BIBLIOTECÁRIAS}

Os portais dos sistemas de biblioteca das dez IES com melhor colocação em qualidade de pesquisa nas regiões norte e nordeste em 2011, conferidos pelo RUF 2012 revelam que esses sistemas estão, majoritariamente, sendo gerenciados de forma antiquada e atrasada. Alguns dos portais visitados tentam colocar-se por trás de designs agradáveis, mesmo quando seu conteúdo não entrega toda a informação de que o usuário necessita. Quando se confronta o contexto social e econômico das regiões em que estão situados e se verificam as práticas descritas e supostamente exercidas, tem-se a percepção de que o código de ética do servidor público civil, a lei de acesso à informação e o código de ética do bibliotecário não foram devidamente assimilados nas ações desenvolvidas e nas informações comunicadas.

Está se evitando afirmar o entendimento de que tudo lá descrito está errado se posto em prática, o que se está a dizer é que a comunicação distribuída pelos 
portais revela que valores éticos previstos no código de ética do bibliotecário não estão expressos como valores que tenham sido levados em conta como referências para as ações previstas.

Nesse sentido, é que se faz notar uma predominante ausência de discurso que tome como princípio que o usuário é capaz, é cidadão. A ausência de documentos de Política de Formação e Desenvolvimento de Coleções é reveladora e consolida uma postura do sistema de manter fechada a base pela qual a comunidade poderia interpretar a adequação da ação, a forma de poder participar, acompanhar o processo de seleção, aquisição, avaliação e desbastamento das coleções e sua articulação com os procedimentos transformados em ações.

Assim, há muito a se fazer para colocar esses sistemas ao dia com a própria Constituição Federal brasileira e com a LAI.

Das informações constantes em alguns portais dessas BUs algumas chamam a atenção. É que revelam de parte de quem autorizou sua publicação, uma incomprensão da realidade do mundo vivido (SCHUTZ, 2003) de hoje, mas, sobretudo por sustentar as ações presentes com base em decisões questionáveis pela inconsistência da argumentação possível. É o caso do texto postado pela UFPB, que não esconde ser o propósito da multa arrecadar receita e, mais, que multa não pode ser abonada, pois representaria renúncia podendo implicar em crime de responsabilidade ao gestor público. Ora, então se a multa é receita como diz a UFPB, mas outras evitam dizê-lo, ela serve para que? Qual sua aplicação? A UFAL responde a isso, com a seguinte afirmação: Todo montante arrecadado de multas será exclusivamente revertido na aquisição de material bibliográfico (livros e revistas).

Sabe-se que em diversos estados da Federação brasileira o Ministério Público Federal tem acionado as IFES orientando-lhes a que se considerem, em cumprimento à Constituição Federal, impedidas de fazer cobrança de taxas para cursos ou emolumentos diversos em função de sua vinculação ao Estado. E nesse caso, como fazer com os discursos acima da UFPB e da UFAL?

Tudo isso mostra, portanto, que requer urgência o dimensionamento do que deve ser tratado visando modernizar esses sistemas bibliotecários que, certamente, refletem a ideologia que predomina nessas universidades, que estão bem em qualidade de pesquisa de acordo com os parâmetros do RUF-2012. O contexto socioeconômico em que esses sistemas estão instalados, o lado exterior da redoma 
que os envolve, requer que eles mudem sua conduta, buscando superar a prática que efetiva uma politica de mau acolhimento humano que aplicam nessas regiões do Brasil.

\section{CONSIDERAÇÕES FINAIS}

Examinar os portais de bibliotecas universitárias, buscando neles encontrar a expressão de ética profissional dos bibliotecários que nelas atuam e que nesse ambiente representam o grupo predominante de STAs, presume a identificação de modalidades de serviços, estratégias de atuação, organização operacional e formas de relacionamento entre profissional e público. Partindo disso, esperava-se encontrar de forma bem esclarecido a ênfase em: respeito ao público, compromisso, responsabilidade social e atuação dignificadora da profissão e da instituição universitária. No contexto brasileiro, considerando as respostas obtidas nesta pesquisa, que envolveu pelo critério de regionalização as vinte melhores IES quanto à qualidade da pesquisa, há ainda significativa distância do atendimento apropriada dessa perspectiva.

Em boa parte dos casos, o bibliotecário não distingue sua ética pessoal de outra disposta na norma ética de sua profissão. Enquanto sua ética pessoal tende a ser utilitária: fazer o melhor quando possível, a ética profissional do bibliotecário brasileiro (CEBB) de cujo artigo terceiro vem o texto do seu juramento profissional é deontológica, ou seja, tudo fazer e fazer bem. Esse choque de posturas tende a colocar a norma ética profissional do bibliotecário no mundo do arquivo matado, das informações insustentáveis, dos saberes que, provavelmente, não são do seu interesse.

E uma resposta contraditando essa ideia não se revelou nesta pesquisa. Em suas duas etapas, a inicial abrangendo as dez primeiras universidades brasileiras por qualidade em pesquisa, segundo o RUF-2012, coincidindo de estarem situadas nas regiões Sul, Sudeste e Centro-Oeste e esta, abrangendo universidades das regiões Norte e Nordeste, não proporcionaram uma resposta que demonstrasse o contrário dessa postura ambivalente. Evidentemente, as BUs selecionadas na primeira etapa ofereceram uma resposta muito melhor que as participantes na segunda etapa, mas, com exceção do portal do SIBI/USP, nenhuma foi muito superior em demonstração discursiva de respeito ao usuário, compromisso e responsabilidade social que a da UFBA. Começa que, das universidades federais 
estudadas, apenas as sediadas no Estado de São Paulo não cobram multas financeiras pelo atraso na devolução de livros e culmina com o portal da UNB contendo a afirmação de que a multa é pedagógica. Uma afirmação grotesca e retumbante, possível apenas como expressão que tende a negar relevância a uma sociedade livre, democrática e cidadã, na qual o sistema federal de ensino superior afirma sua base na gratuidade.

Desse modo, o que se tem ao final do estudo são portais de Bibliotecas Universitárias que oferecem uma expressão muito aquém do desejável em se tratando de ética profissional bibliotecária. $E$ isso abre questão: de onde vem a conduta que leva a esse modo de ação? A leitura do relatório integral da pesquisa, em especial da segunda parte, mostra que a origem, para além do contexto social e econômico, pode estar também nas teorias de gestão (auto) impostas e aceitas pela grande parte dos bibliotecários atuantes na Biblioteca Universitária brasileira, sustentadas em matrizes orientadoras de um eficientismo administrativo e de um gerencialismo esterilizante, como se encontra em alguns textos ali examinados: (BRITO; VERGUEIRO, 2013); (GURGEL; RODRIGUES, 2011), (LUBISCO; VIEIRA, 2009), (PINTO; RODRIGUES, 2012).

\section{REFERÊNCIAS}

BRASIL. Decreto 1.171, de 22 de junho de 1994. Aprova o Código de Ética Profissional do Servidor Público Civil do Poder Executivo Federal. Disponível em: <http://www.planalto.gov.br/ccivil_03/decreto/d1171.htm>. Acesso: 25 jun. 2014.

. Lei 12.527, de 18 de novembro de 2011. Regula o acesso a informações... Disponível em: <http://www.planalto.gov.br/ccivil_03/_ato20112014/2011/lei/l12527.htm>. Acesso: 25 jun. 2014.

BRITO, Gisele Ferreira de; VERGUEIRO, Waldomiro de Castro Santos. Avaliação da qualidade da biblioteca acadêmica: a metodologia Libqual $+\AA$ e suas perspectivas de aplicação no Brasil. BJIS, Marília (SP), v. 7, n. Especial, p. 26-46, 1ํ. Sem. 2013. Disponível em: <http://www2.marilia.unesp.br/revistas/index.php/bjis/article/view/3117/2402>. Acesso em: 4 dez. 2013.

CASTRO, Rosa da Primavera. Ética profissional e interdisciplinaridade: partilha de informação e confidencialidade em sede de equipas multidisciplinares. Gestão e Desenvolvimento, Lisboa, v. 15-16, p. 87-103, 2007-2008. Disponível em: <http://repositorio.ucp.pt/bitstream/10400.14/9083/1/gestaodesenvolvimento15_16_87.p df>. Acesso em: 24 jun. 2014. 
CNPq. Diretório de grupos de pesquisa. Disponível em: <http://lattes.cnpq.br/web/dgp >. Acesso em: 24 jun. 2014.

CONSELHO FEDERAL DE BIBLIOTECONOMIA. Código de ética do bibliotecário brasileiro. 2002. Disponível em: <http://www.cfb.org.br/UserFiles/File/Resolucao/ Resolucao_042-02.pdf>. Acesso em: 18 jun. 2012.

CUARTAS, Enriqueta G. D.; VEIGA PESSOA, Maria Lúcia de M. da; COSTA, Cosme Guimarães da. Código de ética profissional do bibliotecário: 15 anos depois.

Disponível em: <http://repositorio.cfb.org.br/bitstream/123456789/370/1/

Artigo_C\%C3\%B3digo\%20de\%20\%C3\%89tica\%20Profissional\%20do\%20Bibliotec \%C3\%A1 rio\%2015\%20anos\%20depois.pdf>. Acesso: 25 jun. 2014.

ELIAS, Norbert. O processo civilizador. Rio de Janeiro: Jorge Zahar, 1993. 2 v.

GURGEL, Nadsa Maria Cid; RODRIGUES, Maxweel Veras. Biblioteca universitária e ensino superior: em busca de um alinhamento estratégico. Revista EDICIC, v. 1, n. 3, p. 211-228, jul./sep. 2011. Disponível em: $<$ http://www.edicic.org/revista/index.php? journal=RevistaEDICIC\&page=article\&op=view\&path\%5B\%5D=61>. Acesso em: 4 dez. 2013.

INTERNATIONAL FEDERATION OF LIBRARY ASSOCIATIONS AND INSTITUTIONS - IFLA. Código de ética da IFLA para bibliotecários e outros profissionais da informação, 2012. Disponível em:

<http://www.ifla.org/files/assets/faife/codesofethics/ portuguesecodeofethicsfull.pdf>. Acesso: 25 jun. 2014.

LUBISCO, Nídia M. L.; VIEIRA, Sônia Chagas (Org.). Biblioteca universitária brasileira: instrumento para seu planejamento e gestão, visando à avaliação do seu desempenho. Salvador: EDUFBA, 2009. Disponível em:

$<$ https://repositorio.ufba.br/

ri/bitstream/ufba/588/3/Biblioteca\%20universitaria\%20brasileira.pdf>. Acesso em: 8 dez. 2013.

MOTTA, Paulo Roberto; BANDEIRA, Mariana Lima. Responsabilidade pública: os reflexos da diversidade ética na gestão pública. In: CONGRESO INTERNACIONAL DEL CLAD SOBRE LA REFORMA DEL ESTADO Y DE LA ADMINISTRACIÓN PÚBLICA, 8., 2003, Panamá. Anais... Panamá, 2003. Disponível em: <http://unpan1.un.org/intradoc/groups/public/documents/CLAD/clad0047608.pdf>. Acesso em: 24 jun. 2014.

PINTO, Marcella Bernardo; RODRIGUES, Lásara Fabrícia. Avaliação do desempenho de bibliotecas universitárias utilizando a análise envoltória de dados. In: CLAIO/SBPO, 16., 2012, Rio de Janeiro. Anais... Rio de Janeiro, 2012. Disponível em: <http://www2.claiosbpo2012.iltc.br/pdf/101294.pdf>. Acesso em: 4 dez. 2013.

RANKING UNIVERSITÁRIO FOLHA - RUF. As dez melhores universidades. Disponível em: <http://ruf.folha.uol.com.br/2012/>. Acesso em: 24 jun. 2014. 
RIBEIRO, Darcy. A universidade de Brasília. In: REIS, Rodrigo COHN, Sergio; CAMPOS, Simone. (Org.). Darcy Ribeiro: encontros. Rio de Janeiro: Beco do Azougue, 2007. p. 14- 35.

SCHUTZ, Alfred; LUCKMANN, Thomas. Las estructuras del mundo de la vida. Buenos Aires: Amorrortu, 2003.

SOUZA, Francisco das Chagas de. Expressão de ética profissional bibliotecária nos portais dos sistemas de bibliotecas universitárias de IES sediadas nas regiões norte e nordeste do Brasil classificadas como as dez melhores no ranking universitário da folha (RUF) - 2012 por qualidade em pesquisa. 2013. Disponível em: <http://eprints.rclis.org/22570/1/RELATORIO\%20DA\%20PESQUISA\%20\%202a.\%20 etapa.pdf>. Acesso em: 24 jun. 2014.

Valor e sentido do Código de Ética do CFB (Conselho Federal de Biblioteconomia) [CE-CFB] para o bibliotecário brasileiro atuante em biblioteca universitária. Marília: UNESP, 2012. Relatório de pesquisa realizada como atividade de pós-doutorado.

TONIN, Marta Marília. Ética empresarial, cidadania e sustentabilidade. 2010. Disponível em: <http://www.conpedi.org.br/manaus/arquivos/ anais/recife/teoria_da_justica_marta_tonin.pdf. Acesso em: 24 jun. 2014.

UNIVERSIDADE FEDERAL DA BAHIA - UFBA. Universidade Federal da Bahia. Disponível em: <https://www.ufba.br_>. Acesso em: 24 jun. 2014.

UNIVERSIDADE FEDERAL DA PARAÍBA - UFPB. Universidade Federal da Paraíba. Disponível em: <https://www.ufpb.br_>. Acesso em: 24 jun. 2014.

UNIVERSIDADE FEDERAL DE ALAGOAS - UFAL. Universidade Federal de Alagoas. Disponível em: <http://www.ufal.edu.br>. Acesso em: 24 jun. 2014.

UNIVERSIDADE FEDERAL DE CAMPINA GRANDE - UFCG. Universidade Federal de Campina Grande. Disponível em: <Disponível em:

<http://www.ufcg.edu.br/>. Acesso em: 24 jun. 2014.

UNIVERSIDADE FEDERAL DE PERNAMBUCO - UFPE. Universidade Federal de Pernambuco. Disponível em: <http://www.ufpe.br_>. Acesso em: 24 jun. 2014.

UNIVERSIDADE FEDERAL DE SERGIPE - UFS. Universidade Federal de Sergipe. Disponível em: <http://www.ufs.br>. Acesso em: 24 jun. 2014.

UNIVERSIDADE FEDERAL DO CEARÁ - UFC. Universidade Federal do Ceará. Disponível em: <http://www.ufc.br_>. Acesso em: 24 jun. 2014.

UNIVERSIDADE FEDERAL DO PARÁ - UFPA. Universidade Federal do Pará. Disponível em: <http://www.portal.ufpa.br_>. Acesso em: 24 jun. 2014.

UNIVERSIDADE FEDERAL DO RIO GRANDE DO NORTE - UFRN. Universidade Federal do Rio Grande do Norte. Disponível em: <http://www.sistemas.ufrn.br_>. Acesso em: 24 jun. 2014. 
UNIVERSIDADE FEDERAL RURAL DE PERNAMBUCO - UFRPE. Universidade Federal Rural de Pernambuco. Disponível em: <http://www.ufrpe.br>. Acesso em: 24 jun. 2014.

WIKIPEDIA. Lista de unidades federativas do Brasil por incidência da pobreza. Disponível em: <http://pt.wikipedia.org/wiki/Anexo:Lista_de_unidades_federativas _do_Brasil_por_incidência_da_pobreza>. Acesso em: 25 jun. 2014.

Title

Ethics in the library university of North and Northeast of Brazil

\begin{abstract}
Introduction: The notions of social responsibility and good professional practice are forming increasingly in reference to the performance of companies, governments and professions. Brazilian librarians find such notions in the Code of Ethics and the Librarian and internationally in the Code of Ethics of the librarian and other information professionals, IFLA. Objective: To analyze the consolidated discourse in portals libraries of ten universities in the North and Northeast regions of Brazil.

Methodology: Analysis of textual discourse.

Results: Summary of overt attitudes in the portals of BU, referring to behaviors that embrace the relationship with its users.

Conclusions: The librarian does not distinguish between your personal ethics and the ethical norm of their profession. While his personal ethics is utilitarian, professional ethics code of ethics prepared in the Brazilian librarian is deontological. The portals of University Libraries offer a studied expression very much to be desired when it comes to professional ethics librarian.
\end{abstract}

Keywords: Professional ethics; Librarian ethics; Brazil - university library.

Título

La ética en la biblioteca universitaria de Norte y Noreste de Brasil

Resumen

Introducción: Las nociones de responsabilidad social y las buenas prácticas profesionales están formando cada vez más en relación con el desempeño de las empresas, los gobiernos y las profesiones. Bibliotecarios brasileños encuentran tales nociones en el Código de Ética y el Bibliotecario, a nivel internacional, en el Código de Ética de los profesionales de la información bibliotecario y otros, de la IFLA. 
Objetivo: Analizar el discurso en los portales de diez bibliotecas de universidades de las regiones Norte y Nordeste del Brasil.

Metodología: Análisis del discurso textual.

Resultados: Resumen de las actitudes manifiestas en los portales de la BU, que se refieren a conductas que abarcan la relación con sus usuarios.

Conclusiones: El bibliotecario no distingue entre su ética personal y la que organiza la norma ética de su profesión. Mientras que su ética personal es utilitaria, el código de ética profesional es deontológica. Los portales de bibliotecas universitarias ofrecen una expresión que deja mucho que desear cuando se trata de la ética profesional bibliotecario.

Palabras clave: La ética profesional. Ética del bibliotecario. Brasil - biblioteca de la universidad.

Recebido em: 10.09 .2014

Aceito em: 22.05.2015 